\title{
Commentary: The environment matters: The effects of passive circulation are not quickly reversed by a change of heart
}

\author{
Karthik Thangappan, MD, and David L. S. Morales, MD
}

\footnotetext{
From the Department of Cardiovascular Surgery, Cincinnati Children's Hospital Medical Center, Cincinnati, Ohio.

Disclosures: Dr Morales discloses the following: consultant and member of medical advisory board for Berlin Heart, Inc; proctor, consultant, and member of medical advisory board for Syncardia, Inc; national primary investigator for the 50/50cc Syncardia Total Artificial Heart Food and Drug Administration trial; consultant for Medtronic, Inc (HeartWare Division); consultant for Abbott Medical, Inc (Thoratec Division); and consultant, investigator, and member of medical advisory board for CorMatrix Cardiovascular, Inc. Dr Thangappan has nothing to disclose with regard to commercial support.

Received for publication Sept 23, 2019; revisions received Sept 23, 2019; accepted for publication Sept 24, 2019; available ahead of print Oct 31, 2019.

Address for reprints: David L. S. Morales, MD, Department of Surgery, Department of Cardiovascular Surgery, Cincinnati Children's Hospital Medical Center, 3333 Burnet Ave, MLC 2004, Cincinnati, OH 45229 (E-mail: David.Morales@cchmc.org).

J Thorac Cardiovasc Surg 2020;159:2001-2

$0022-5223 / \$ 36.00$

Copyright (C) 2019 by The American Association for Thoracic Surgery

https://doi.org/10.1016/j.jtcvs.2019.09.092
}

The article in the Journal by Stephens and colleagues ${ }^{1}$ astutely illustrates the concept of how poor hemodynamics as a result of passive circulation in single-ventricle (SV) patients (eg, Glenn and Fontan circulations) can impact posttransplantation management and the extended length of time to achieve "normal" hemodynamics. Conversely, most patients who undergo heart transplantation for dilated cardiomyopathy normalize in 3 months and nearly all normalize in 6 months. The article delves into the specifics of hemodynamic follow-up and illustrates the different time frames for specific cardiac hemodynamics to normalize in each cohort.

SV physiology, or passive circulation, as exists in Glenn and Fontan patients, can lead to numerous changes in the body that a new transplanted heart will have to deal with as soon as it is implanted. This includes but is not limited to liver congestion, chronic underfilling of the SV causing restrictive physiology, an abnormally adapted pulmonary vascular bed, and systemic-pulmonary collateral formation. In fact, as a result of these changes, pulmonary vascular resistance is usually greater than we can actually measure in SV patients and often causes some aspect of right heart failure. Also contributing to this is the increase in blood products often required after transplanting a Fontan patient. In addition, the massive collateral burden seen in end-stage Fontan circulation does not abate quickly with transplantation, thus exposing the new heart to significant volume overload, which may explain why left ventricle end-diastolic pressure is often the last hemodynamic parameter to normalize. Therefore, these are forces a new heart will have to work against from the start and

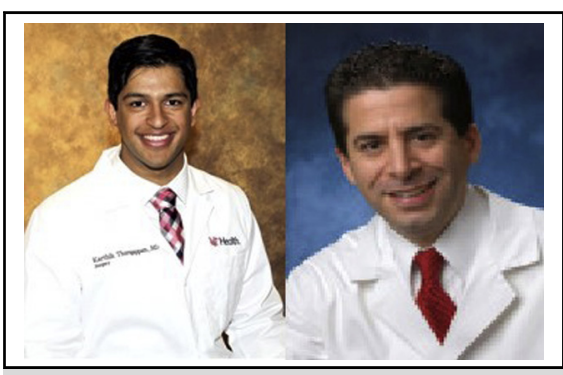

Karthik Thangappan, MD (left), and David L.S. Morales, MD (right)

Central Message
Single-ventricle physiology creates an environ-
ment that is challenging for a new heart to
normalize; however, with time, the effects left
behind by the passive circulation will eventu-
ally improve.

See Article page 1986. attempt to normalize over time. These features are not as prominent in dilated cardiomyopathy heart failure and as a result a new heart does not need to accommodate to as hostile of conditions upon implantation in these patients, resulting in comparatively quicker normalization of hemodynamic parameters.

Interestingly, the article does not clarify whether the SV patients are more clinically ill pre- or posttransplantation, as the authors did not share data on such things as feeding tolerance and end-organ function, both of which are important risk factors for delayed posttransplantation clinical and hemodynamic recovery. ${ }^{2}$ This information would reveal whether the delay in hemodynamic recovery is purely due to the effects of SV physiology or whether the clinical status of the SV patients pre- and posttransplantation contributed as well.

The article by Stephens and colleagues ${ }^{1}$ does a great job illustrating in detail a clinically observed but not previously published phenomenon that hemodynamics posttransplantation often take longer to normalize in SV patients versus patients with heart failure. A good heart will struggle at first to improve the hostile environment left behind by SV circulation; however, if the environment is not too far gone, then the deleterious effects of the passive circulation can improve with just a change of heart. 


\section{References}

1. Stephens E, Tannous P, Monge MC, Eltayeb O, Backer CL, Forbess JM, et al. Normalization of hemodynamics is delayed in single ventricle patients after pediatric heart transplantation. J Thorac Cardiovasc Surg. 2020;159:1986-96.
2. Pincott ES, Burch M. Indications for heart transplantation in congenital heart disease. Curr Cardiol Rev. 2011;7:51-8. 